Lymphstrom in jenem grossen Zuflussgebiet des Herzens erheblich $\mathrm{zu}$ beschleunigen.

Auch hier hätten wir also nur wieder eine neue Analogie zu dem Verhalten des Blutherzens gefunden ${ }^{1}$ ).

Jene Stillstände der Lymphherzen, welche öfters einer Abtrennung des Centralmarkes folgen, dürften jetzt wohl auch auf den gleichzeitig gewiss erheblich geschwächten Lymphstrom zu beziehen sein.

(Physiol. Laboratorium der Thierarzneischule Bern.)

\title{
Zur Theorie der Reflexe.
}

\author{
(Drittekurze Mittheilung.) ${ }^{2}$ )
}

Von

\section{R. Iuchsinger.}

Fortgesetzte Untersuchungen uiber die Reflexgesetze der Thiere haben mir eine reiche Fülle weiterer Erscheinungen aufgedeckt, im folgenden seien einige jetzt schon kurz skizzirt; eine weitere Bearbeitung des Gebietes ist unternommen, und eine ausfubriliche, zusammenhängende Darstellung soll später folgen

I. Betäubt man irgend ein beliebiges Insect durch Aether oder durch Erstickung vollkommen und lässt dann Wiedererholung eintreten, so sieht man leicht ein Stadium, wo die Spontaneität noch nicht zurückgekehrt ist, wohl aber die Reflexfähigkeit sich restituirt hat.

Zupfe ich einer so narkotisirten Grille talpa ein Mittelbein, fasse ich es sorgfältig mit feiner Pincette an einer seiner Borsten

1) Vgl. Ludwig u. Luchsinger, Med. Centralbl. 1879, sowie die domnächst folgende ausführliche Mittheilung.

2) vgl. B. Luchsinger, Tagebl. der deutschen Naturforscher in Baden-Baden 1879. 255; dies Archiv, XXII. 179. 1880. 
und führe damit passive Gehbewegungen aus, so sieht man entsprechende Bewegungen auch im Hinterbein der andern Seite auftreten. Dasselbe geschieht mit dem gekrenzten Mittelbein, wenn ich ein Hinterbein in entsprechender Weise behandle.

Dagegen sind von dem Vorderbein nur gleichseitige Wirkungen zu erzielen.

Die Locomotion der Grille ist ein einfaches Trabgehen, aber sie benutzt hiezu nur Mittel- und Hinterbein, und dienen die Vorderbeine ausschliesslich als Grabschaufeln.

Nehmen wir nun aber einen Carabus, einen Hydrophilus, so gelingen gleiche Versuche auch am Vorderbein. In günstigen Fällen kann man sogar doppelte Kreuzung sehen, indem hier Reizung eines Vorderbeins Bewegung im gekreuzten Mittelbein, aber auch noch Bewegung im gleichseitigen Hinterbeine zeigt.

Betrachten wir aber die Locomotion dieser Thiere, so sehen wir eine Coordination des Vorderbeines und Hinterbeines der gleichen, des Mittelbeines der andern Seite.

Damit zeigen sich auch hier - wie bei den trabgehenden Wirbelthieren - die Aeusserungen des Nervensystems vollkommen conform den Verhältnissen der Locomotion. Wenn aber in Thierklassen, die sonst durchaus nichts mit einander gemein haben, gleicher Locomotion auch gleiche Reflexgesetze entsprechen, so muss ein tiefer, ein causaler Zusammenhang zwischen beiden Erscheinungen walten.

II. Köpft man einen Triton, und hängt ihn an einem Stativ frei schwebend in die Luft; so sieht man auf leis e mechanische Reizung des Schwanzes denselben sich nach dem reizenden Punkte zuwenden, sticht man aber mit der Spitze des Messers nach ihm, so weicht er in bekannter Weise dem Reize aus.

In gleicher Art, nur weniger leicht, gelingt der Versuch am Molch, an der Eidechse, am Aal; aber er gelingt auch an der Natter.

Eine Schlingnatter wurde geköpft. Sanftes Streicheln des Schwanzes lässt denselben sich dem Reize zuwenden; Stechen, noch mehr Anglühen aber rufen ein Wegwenden des Schwanzes hervor.

Appliciren wir schwache Reize dem Rumpfe, so sehen wir ein Einziehen desselben, folgt dagegen starken Reizen ein Vorwölben gegen den Reiz hin. 
In seinen berühmten Versuchen am Aalschwanz sah Pflüger unter normalen Bedingungen stets nur ein Ausweichen des Schwanzes; anderseits nahm aber Tiegel bei Schlangen stets nur ein $\mathrm{Zu}$ wenden des Schwanzes wahr.

Unsere Versuche versöhnen jene scheinbaren Widerspriiche, indem sie die verschiedenen Resultate dieser Forscher auf eine verschiedene Reizstärke zurüickführen.

Diesen verschiedenen Reizstärken aber weiss das normale Rückenmark in verschiedener, aber jedesmal zweckmässiger Weise za antworten.

Schwachen Reizen entspricht ein Annähern des Schwanzes, also beim intacten Thier auch ein Annähern des ganzen Thieres. Starken Reizen aber wird mit Abwenden des Schwanzes, einem Fluchtsymptom des normalen Thieres entgegnet. Die Taxation derReizstärke aber wird von dem Rückenmarke verschiedener Thiere in verschiedener Weise besorgt.

Was für eine Thierart ein starker Reiz, kann noch als schwach für eine andere gelten.

Wird das Präparat alt, so ändern sich die Erscheinungen. Die zunehmende Erstickung des Gewebes wirkt wie kleine Dosen Strychnin.1) Milde Reize werden als starke empfunden, starke Reize aber verlassen die gewohnten Reflexbahnen und irradiiren in das gesammte Rüekenmarksgrau, bewirken dementsprechend wieder ein Ueberwiegen der Muskeln der gereizten Seite, lassen den Schwanz wieder hineinschlagen ins Feuer. Ein erstickendes Rückenmark kann sich damit schwachen und starken Reizen gegenüber gerade umgekehrt verhalten wie ein normales, $d . \mathbf{h}$. frisch geköpftes, indem es bei schwächerem Reize schon flieht, bei starkem Reize aber jählings in die Gefahr hineingerissen wird.

III. Vor kurzem hat Langend orff von einem gekreuzten Reflex am Frosch berichtet. Sanftes Streicheln der Wange mache Bewegungen des Hinterbeins der andern Seite.

Ich kann hinzufügen, dass auch schwache Reize anderer Hautflächen dasselbe bewirken; während wie auch Langendorff richtig angiebt, starke Reize eine Bewegung des gleichseitigen Hinterbeines auslösen. Betrachten wir die Locomotionsverhältnisse

1) Vgl. Pflüger, die sensor. Function. d. Rückenmarkes. Berlin. 1853. S. 116. 
des Frosches, so begreifen wir sofort, dass auch diese Reactionen in dieselbe Kategorie von Erseheinungen gehören, wie wir sie eben jetzt für das Schwanzmark verschiedener Thiere angedeutet haben.

Bei mildem äussern Reize wird der intacte Frosch heran schwimmen wollen, also mit dem Hinterbeine der andern Seite stevern müssen, bei starkem Reize aber flieht er und hat dabei wesentlich mit dem Hinterbeine der gleichen Seite zu arbeiten.

Nähern wir der Wange des enthirnten Frosches einen glühenden Körper, so sehen wir in der That ein deutliches Wegwenden des Kopfes - eine der Pflüg e r'schen Beobachtung am Aalschwanz doch vollkommen identische Erscheinung! War der Reiz stärker, so erfolgt dann Wegspringen des Thieres.

IV. Hat man einem Frosch das Grosshirn, oder auch noch dazu das Mittelhirn entfernt, so kann er sich bekanntlich auf den Rïcken gelegt, immer wieder in die Bauchlage drehen.

Legt man ihn derb auf den Rücken, so wendet er sich sofort um, legt man ihn aber hehutsam auf eine glatte Unterlage, und lässt nur sehr allmählich die Hand los, so kann er lange Zeit in der abnormen Lage verweilen. Erst ein hinzutretender Reiz vermag ihn zur Umkehr zu wecken.

Diese Umdrehung kann aber auf zweierlei Art geschehen und wird dies von der Stärke und Richtung des angewandten Reizes abhängen.

In der That streicheln wir irgend einen Punkt des Rumpfes, am besten das Vorderbein leise, so sehen wir das Thier sich dem Reize zuwenden und geschieht die Drehung in der Weise, dass die Bauchfläche sich dem Reiz zukehrt.

Nähern wir uns aber dem hirnlosen Thier von der Seite mit einem brennenden Zündhölzchen, so geschieht die Umkehr in entgegengesetzter Richtung, wendet sich die Bauchfläche des Thieres von dem Reize weg.

Entsprechend dem verschiedenen Ziel ist die erforderliche Muskelaction auch eine verschiedene.

Beim Zuwenden ist wesentlich das Hinterbein der andern, beim Wegwenden aber das Hinterbein der gleichen Seite betheiligt.

Also auch hier sehen wir, wie bei dem Versuche am Schwanzmark, ein verschiedenes Verhalten des enthirnten Nervensystems gegen äussere Reize. 
Ganz analoges Verhalten zeigten andere Thiere, so Triton und Alpenmolch.

Es weiss anch das ,entseelte“ Thier sieh änsserst passend nach den äussern Umständen zu richten.

Eine weitere Bearbeitung dieses eben erst in Angriff genommenen Gebietes behalte ich mir selbstverständlich vor. 